\title{
Negative emotions in informal feedback: The benefits of disappointment and drawbacks of anger
}

human relations

2014, Vol. 67(10) 1265-1290

(C) The Author(s) 2014

Reprints and permissions:

sagepub.co.uk/journalsPermissions.nav DOI: I0.II77/00|87267|4532856 hum.sagepub.com

(SAGE

\section{Genevieve Johnson}

University of Oklahoma, USA

\section{Shane Connelly}

University of Oklahoma, USA

\begin{abstract}
Using the emotions as social information (EASI) model, this study investigated the emotional, attitudinal and behavioral reactions to failure feedback by manipulating negative emotional displays (angry, disappointed or none) and the position level and relational distance of the feedback source. Undergraduate students $(N=260)$ responded to an organizational failure feedback vignette and completed a subsequent performance task. Results demonstrated that guilt was the complementary emotional experience following displays of disappointment, while reciprocal anger followed displays of anger. These emotional reactions served as important mediators between the emotional displays paired with the feedback message and participant responses of social behaviors, creative task performance and perceptions of the feedback source. In addition, our findings indicated that negative emotions can have positive organizational and interpersonal outcomes. Guilt in response to disappointed displays resulted in beneficial behaviors and attitudes, while anger in response to angry displays was socially detrimental. The emotion displayed during feedback provision also served as a consistent contextual factor that did not interact with the position level or relational distance of the feedback source to impact behavioral and attitudinal reactions. Overall, this study
\end{abstract}

\footnotetext{
Corresponding author:

Genevieve Johnson, Department of Psychology, University of Oklahoma, Center for Applied Social Research, 3100 Monitor Ave, Suite 100, Norman, OK 73072, USA.

Email: johnson.gen@ou.edu
} 
indicates that discrete negative emotions have unique social-functional properties that require further investigation.

\section{Keywords}

anger, disappointment, EASI, emotional display, emotions as social information, guilt, performance feedback

Emotions are gaining momentum in their importance at work (see Ashkanasy and Humphrey, 2011; Brief and Weiss, 2002), but a great deal of the literature on affective states in the workplace has revolved around the tendency for researchers and theorists 'to argue for the inherent goodness of positive emotion and the inherent badness of negative emotion' (Elfenbein, 2007: 325). These comparisons have also focused on the overall positive and negative valence of affective displays and experiences at work (Brief and Weiss, 2002). However, many theorists have long noted the valuable roles discrete negative emotions may play (e.g. Keltner and Haidt, 1999), and organizational contexts in which negative emotions are common, such as failure feedback (Baron, 1988; Gaddis et al., 2004; Hareli and Hess, 2008), offer critical opportunities for investigating the potential benefits of specific negative emotions.

Feedback is an important part of the daily functioning of organizations by directing effective behavior and performance (Steelman and Rutkowski, 2004). However, feedback interventions can be detrimental up to one-third of the time (Kluger and DeNisi, 1996). Variability in feedback effectiveness may be owing to the emotions involved in feedback exchanges, but the literature's focus has been on the affect induced by the feedback message itself as opposed to the emotional displays commonly paired with the feedback message (e.g. Ilgen and Davis, 2000; Ilies et al., 2007; Kluger and DeNisi, 1996 - see Gaddis et al., 2004 for an exception). Furthermore, the modernday workplace affords a number of opportunities to study the impacts of emotional displays in feedback provision. Informal feedback communicated outside the realm of formal, standardized appraisal processes (Fedor et al., 1989) is important but has been largely ignored by researchers (Pulakos and O'Leary, 2011). Feedback communications can also occur through a number of media ranging from face-to-face to computer-mediated interactions, and most research has focused on these media for formal feedback processes (e.g. Payne et al., 2009). Computer-mediated communication such as email is also becoming increasingly integral to an organization's effectiveness (Santra and Giri, 2009), and feedback provided via email is gaining acceptance (Baker, 2010).

To address these gaps, this study expands the emotions as social information framework (EASI; Van Kleef, 2009) to a computer-mediated, informal feedback situation to help understand how discrete negative emotional displays (i.e. disappointment and anger) and other contextual factors impact feedback receivers' state emotions, attitudes and behavior. 


\section{Emotions as social information}

By extending Schwarz's (1990) feelings-as-information idea, the EASI model (Van Kleef, 2008, 2009) is grounded in a social-functional approach to emotion, where emotional displays provide information not only to the self but also to others as well (Keltner and Haidt, 1999; Van Kleef, 2009). The significance of the EASI model is its assertion that each discrete emotion conveys unique information, leading to distinct cognitive and behavioral responses contingent on the information provided via the emotion expressed (Van Kleef, 2009). Essentially, these responses are the result of processes such as the experience of reciprocal or complementary emotions (Keltner and Haidt, 1999) and can be moderated by social-relational factors, helping individuals to determine the perceived appropriateness of emotional displays (Van Kleef, 2009). The EASI is especially relevant to feedback in organizations because the emotions displayed by feedback givers, whether deliberate or not, may convey cues indicating satisfaction or dissatisfaction with the receivers' work behavior. Personal affective reactions are the first pieces of information that people use to interpret feedback messages (Ilies et al., 2007). As a result, the elicitation of emotional reactions via others' emotional displays helps individuals interpret feedback situations and determine how to deal with the challenges posed by the social environment (Fischer and Manstead, 2008).

The induction of negative emotions in feedback situations might not always lead to adverse outcomes, especially with regard to the goals of a feedback provider. For example, the experience of negative affect is undesirable and may result in corrective action to close performance gaps (Kluger et al., 1994) or to improve personal relationships (Fischer and Manstead, 2008), but the degree to which this occurs may depend on the specific emotion evoked. Several studies have demonstrated that different negative emotional displays have different effects on observers (Connelly and Ruark, 2010; Lelieveld et al., 2011; Lewis, 2000). However, such research has focused on emotions such as anger and sadness (e.g. Lewis, 2000; Tiedens, 2001), and Van Kleef (2008) noted the need to research the impacts of discrete negative emotions other than anger, such as guilt and disappointment. We therefore compare the impact of two emotional displays, anger and disappointment, in feedback situations.

\section{Anger}

People tend to express anger, intentionally or unintentionally, when they think they can correct the behavior of another person (Fischer and Roseman, 2007), thereby regulating interpersonal and social behavior (Fischer and Manstead, 2008). Anger may be particularly relevant in feedback situations as it can signal dissatisfaction and the need for change to avoid future goal frustration (Fischer and Roseman, 2007; Van Kleef et al., 2010). Although anger may be seen as a way to change another's behavior, it typically has negative ramifications. Threatening anger displays commonly elicit reciprocal anger (Lelieveld et al., 2012; Wubben et al., 2009). Displays of anger communicating blame and responsibility of others for a negative event (Lerner and Tiedens, 2006) can be perceived as unjustified and lead to reactions of anger (Elfenbein, 2007). Perceptions of unfairness or injustice regarding the anger display, especially in the interpersonal sense, 
are common causes for workplace anger (Barclay et al., 2005; Gibson and Callister, 2010), and taking personal offense to angry accusations is also likely to evoke angry reactions (Lerner and Tiedens, 2006).

\section{Disappointment}

Expressing disappointment in a person communicates that one had higher expectations of that person or had hoped for more from them, evoking feelings of social responsibility (Lelieveld et al., 2012; Zeelenberg et al., 2000). As a result, people may deliberately express disappointment to change the behavior of others in desired ways (Lelieveld et al., 2011; Wubben et al., 2009). Since behavior modification via communication of needed improvements is the goal of feedback, disappointment may be especially salient in this context. Research has shown that displays of disappointment can produce interpersonal effects such as helping behavior or concessions that have been seen with other distress-related emotions (Van Kleef et al., 2006), which may be owing to the emotional response of guilt to a display of disappointment.

As a self-conscious evaluative emotion (Lewis, 2008; Tangney, 1995), guilt operates in situations in which one believes one has harmed or disappointed another person (Baumeister et al., 1994). Contrary to the other-referencing nature of anger, guilt is a self-referenced emotion in which one feels personal responsibility for an event through internal attribution of causes (Hareli and Hess, 2008; Neumann, 2000). Since the level of undesirability is appraised in light of a violation of social norms (Lewis, 2008), the experience of guilt can indicate that the other person in the relationship has different standards or expectations for behavior (Sommer and Baumeister, 1997), similar to what a display of disappointment signals. With the exception of recent research on negotiation (Lelieveld et al., 2011) and other research on interpersonal functions (Ferguson et al., 1997; Vangelisti et al., 1991), the induction of guilt via displays of disappointment has rarely been directly considered. However, such research has shown that disappointment leads to complementary feelings of guilt (Lelieveld et al., 2012), and we extend this concept to failure feedback in work contexts:

Hypothesis 1a: Emotional displays of anger during feedback will lead to significantly higher levels of experienced anger than will displays of disappointment.

Hypothesis $1 b$ : Emotional displays of disappointment during feedback will lead to significantly higher levels of experienced guilt than will displays of anger.

\section{Differential effects of experiencing feelings of anger and guilt}

The directional focus and attributions of blame and responsibility (i.e. other versus self) linked to anger and guilt (Smith and Ellsworth, 1985; Weiner, 1986) have critical implications for behavioral and attitudinal outcomes, including why one might be more beneficial than the other in failure feedback. Furthermore, investigations of behavioral responses within social-functional frameworks have typically focused on interpersonal variables, while most existing research on feedback has focused on performance for 
tasks similar to the original feedback-originating task (e.g. Saavedra and Earley, 1991). This study extends both lines of research by investigating a range of outcomes including social behaviors, evaluations of the feedback source and task performance.

\section{Social behaviors}

Displays of disappointment have been linked to positive social reparative behaviors, which may occur owing to the feelings of guilt associated with observing a disappointed emotional display (Lelieveld et al., 2011). Westen (1994) found that reparative responses such as apologizing, helping someone or doing good deeds were the most frequently used strategies in response to feeling guilty. Confessing to the negative action (Baumeister et al., 1994), acceptance of the wrongdoing and taking responsibility for the action (Tangney, 1995) are also common. Since guilt communicates concern regarding one's effects on others that stem from offending behavior (Tangney, 1995), individuals feeling guilty are motivated to engage in positive social behaviors in an attempt to amend or restore the relationship and alleviate feelings of guilt (Ketelaar and $\mathrm{Au}, 2003$ ). Thus, guilt functions to enhance our interpersonal relationships (Sommer and Baumeister, 1997) by regulating aversive affect (Westen, 1994).

Anger results in less positive social or reparative behaviors. For example, angry displays resulted in lower levels of cooperation than disappointed displays (Wubben et al., 2009) and prompted competitive and retaliatory behavior (Van Kleef and Côté, 2007). In fact, whether evoked by angry displays or not, angry individuals have a tendency towards negative social retaliatory behaviors (Gibson and Callister, 2010; Lerner and Tiedens, 2006) such as hostility, antisocial behaviors and avoidance of the person who prompted the anger (Fitness, 2000). Moreover, owing to the other-referencing nature of anger, angry individuals tend to attribute blame more to others (Lerner and Tiedens, 2006), as opposed to taking action to amend the situation. Drawing on past research, this study considers positive social behaviors of apologizing, accepting responsibility and promising to work harder in the future and negative social behaviors of making excuses and shifting blame. We also propose that the emotional reactions of guilt and anger will mediate the relationship between the emotional display paired with the failure feedback and these downstream social behaviors:

Hypothesis 2a: Emotional displays of disappointment when providing failure feedback will result in more positive social behaviors and fewer negative social behaviors from the recipient than will displays of anger.

Hypothesis 2b: These effects will be mediated by higher levels of experienced guilt following a disappointed display and higher levels of experienced anger following an angry display.

\section{Impressions of the feedback source}

According to the EASI model, evaluations of the person displaying emotion are influenced by the social intentions or relational orientations that expressions of emotion convey (Van Kleef, 2009). In general, negative affective displays can lead to less positive evaluations of supervisors or peers in terms of competence, effectiveness or likeability 
(Connelly and Ruark, 2010; Lewis, 2000; Visser et al., 2013). However, evaluations may differ depending on the specific negative emotion displayed, and research has found differential effects of discrete negative emotions such as anger and sadness on competence and likeability evaluations (Tiedens, 2001).

At the interpersonal level, research has shown that anger reduces the quality of the interpersonal climate and leads to the development of negative feelings and impressions of one's counterpart or colleague (Tiedens, 2001; Van Kleef, 2009), including a reduction in trust (Lerner and Tiedens, 2006). Work teams with angry leaders also developed negative impressions and lower levels of liking of these leaders (Van Kleef et al., 2009). Disappointment, however, may seem less threatening and have fewer negative impacts on evaluations of others. If disappointed displays evoke self-evaluative guilt as hypothesized, recipients may be more upset with themselves than with the people providing the feedback. For example, Dunn and Schweitzer (2005) found that, relative to angry individuals, guilty participants had more willingness to trust others, indicating a less damaged view of relationships. Feeling guilty also signals that a relationship is important (Baumeister et al., 1994) and deserves respect (Fischer and Manstead, 2008), resulting in seeing the relationship in a more positive light than when angry. Accordingly:

Hypothesis 3a: Feedback recipient evaluations of the feedback source will be more positive when the source displays disappointment versus anger.

Hypothesis 3b: These effects will be mediated by higher levels of experienced guilt following a disappointed display and higher levels of experienced anger following an angry display.

\section{Performance}

Guilt can be linked to performance, as task failure may be seen as a violation of workplace social standards (e.g. adequate performance, success on tasks, completing responsibilities) (Gruenewald et al., 2007). Since guilt is an active self-conscious emotion associated with corrective behaviors aimed at repairing normatively based failure (Gruenewald et al., 2007; Lewis, 2008), feeling guilty can be a strong motivation for reparative actions (e.g. Ketelaar and $\mathrm{Au}, 2003$ ), including task performance. Specific to the context of failure feedback, reactions of guilt might indicate that the displays of disappointment are perceived as more procedurally or interactionally justified (Barclay et al., 2005) because employees recognize that they violated an expectation, leading them to accept the blame and make amends.

As for anger, the results have been mixed depending on the nature of the task and the situation in which the anger was induced. For instance, feeling angry can lead to ineffective strategies for handling extant performance issues (Baron, 1988) and lower-quality solutions (Thiel et al., 2012). Another possibility is that displays of anger can force cooperation by announcing possible retaliation (Wubben et al., 2009) such that the causal anger can pressure one to yield (Fischer and Manstead, 2008). For creative performance tasks, active negative emotions such as anger can increase cognitive persistence and resulting performance (De Dreu et al., 2012). Therefore, although performance is affected, it may not be as high as when feeling guilty because the performance is coerced by another instead of the self. This leads to the fourth set of hypotheses: 
Hypothesis 4a: Performance will be of higher quality following failure feedback when the feedback source displays disappointment versus anger.

Hypothesis $4 b$ : These effects will be mediated by higher levels of experienced guilt following a disappointed display and higher levels of experienced anger following an angry display.

\section{Social-relational moderators and their influence}

Research and theory also suggest that situational factors influence behavioral reactions to failure feedback (Ilgen et al., 1979; Kluger and DeNisi, 1996; Steelman and Rutkowski, 2004). Informal feedback can come from a variety of sources ranging from supervisors, to peers, to customers (Audia and Locke, 2003), and these sources can be a close friend or a casual contact. Therefore, this study proposes two moderators that may impact the reactions to disappointed and angry displays when applying the EASI framework: position level and relational distance. Previous research has called for consideration of the impact of social distance on perceptions of emotional displays (Connelly and Ruark, 2010) and expansion of organizational research beyond leader-follower relationships, as coworker relationships are also key to an organization's success (Madlock and BoothButterfield, 2012).

Overall, more leeway is given to leaders' negative emotional displays (Gibson and Schroeder, 2002), and people associate the expression of anger with high status, power and competence (Tiedens, 2001). Feedback from a higher-status source also tends to be more accepted and seen as more useful (Herold et al., 1987; Ilgen et al., 1979). In addition, individuals tend to be more attuned to feedback from sources closer to them (Ilgen et al., 1979; Kanfer et al., 1974). When receiving failure feedback from these various sources, however, the impact of the emotional display may differ. In the workplace, coworkers, especially those with whom one has close relationships, are seen as important sources of support in stressful or threatening situations - notably, emotional support (Lawrence, 2006). Although negative emotional displays in failure feedback may not appear highly supportive overall, disappointment in failure feedback may be seen as more acceptable than anger because it may communicate higher confidence in the person's abilities. As a result, fewer expectancy violations regarding anticipated support, especially from those in close and/or coworker relationships, may reduce negative reactions. Guilt is also more exclusive to close relationships (Baumeister et al., 1994; Lewis, 2008; Vangelisti et al., 1991), underscoring the increased impact and acceptability of disappointment from those close to oneself. Angry, close coworkers may therefore be seen as particularly violating interpersonal expectations or overstepping workplace roles and boundaries. It is less clear how reactions to leaders with various emotional displays and degree of relational closeness will function owing to fewer constraints on accepted emotional expressions and lower expectations regarding emotional support. We therefore ask:

Research question 1: How do the emotional display, position level and relational distance of the feedback source interact to impact social behaviors, evaluations of the source and performance? 


\section{Method}

\section{Participants}

Participants included 260 undergraduate students at a large southwestern university in the USA who completed this study using a web-based data collection system. Participants volunteered to complete this study to obtain research credit for a psychology course. The mean age of the participants was $18.89(\mathrm{SD}=1.88)$ and 79.6 percent were female $(n=207)$.

\section{Design}

In order to test the proposed hypotheses, a $3 \times 2 \times 2$ between-subjects design was used, resulting in 12 total conditions to which participants were randomly assigned. The first variable, emotional display (angry, disappointed or neutral), was manipulated via both wording and tone of a fictitious work email received by the participant containing failure feedback. The source of the email (i.e. the feedback source) varied along two dimensions that were manipulated in the background information given to the participants: position level (supervisor versus coworker) and type of relationship between the participant and the feedback giver (close versus distant).

\section{Procedure}

First, participants completed a battery of covariate measures. Following the covariates, the participants were asked to take on the role of a marketing specialist for a large fictional consulting firm named Epi-Cure Consulting Group. Participants were provided with background information on the marketing company, a description of their job and a delineation of their relationship with Mark Turner, the individual who provided simulated feedback at a later point in the study, in both written form and in an organizational chart. Next, participants were presented with a fictitious situation involving two emails from Mark about a recently completed project. The first email served as a check-in and deadline reminder from Mark. The participants were told that they were finishing up the project when they received the email and, although they noticed a few mistakes, they went ahead and submitted the project in order to meet the deadline. The second email mentioned the unsuccessful outcome of the project and included feedback from Mark. Participants were then prompted to respond by writing out an email and describing any actions they would take, being specific in describing their thoughts, feelings and actions. After completing their response, participants read another email from Mark asking for assistance on a new assignment (i.e. restaurant design plan). The participants then read the task description and were asked to complete the assignment to the best of their ability. Afterwards, participants completed the manipulation check measures, reported their perceptions of Mark and completed demographic measures.

\section{Manipulations}

The feedback provider, Mark Turner, was consistently portrayed as a male to avoid a confound, as there is evidence that negative emotions such as anger are seen as more 
acceptable when displayed by a male than by a female leader (Lewis, 2000). The background information on the organization and the position was identical for each participant, which stated that they had been working as Jordan Gilmore, a marketing specialist within the Restaurant Design and Startup Division of Epi-Cure Consulting Group, for five years.

Emotional display. Each participant read a failure feedback email that expressed either disappointment, anger or a neutral level of emotion in tone and wording. The disappointed email reflected the types of messages usually paired with disappointment displays, that is, that the results were worse than expected (Van Dijk and Zeelenberg, 2002) and that the individual fell short of expectations (Zeelenberg et al., 2000). The angry email was based on typical expressions of anger involving other-blame (Fischer and Manstead, 2008) and a tendency to attack (Fitness, 2000), conveying the emotion through active negatively charged words, capitalized words and multiple exclamation marks. The control email consisted of neutral emotionality such that, although the feedback was still negative, there was no clear or strong emotion that could be detected via the wording and tone. The number of words and content of the message unrelated to the manipulations were kept as parallel as possible across conditions (examples in Appendix).

Social-relational variables. The first manipulated social-relational variable, position level, delineated whether the participant was interacting with a leader (their boss) or a peer (their coworker). Both condition types noted that Mark had worked at Epi-Cure for 10 years so that those in the peer conditions still viewed Mark as a more experienced coworker to make the feedback situation more plausible. The second social-relational variable, relational distance, was manipulated such that participants in the close conditions read that they had a close relationship with Mark and that they had gotten to know him well and considered him a friend. The distant group read the opposite. Both conditions do mention, however, that the participant valued Mark's personal and professional opinion so the feedback would be seen as viable.

\section{Outcome variables}

Emotional reactions. Angry and guilty affective reactions to the failure feedback were measured by rating the emotions displayed in the participants' responses. Three independent, trained PhD students, who were blind to conditions and the nature of the experiment, rated each response on a five-point Likert scale on extent of emotion expressed (1 $=$ 'Not at all', $5=$ 'Great extent'). Ratings were based on both explicit discussions of emotions and inferences made of emotionally charged words and actions (e.g. defensive responses for anger or feeling personally responsible for guilt). By rating expressions of internal cognitive processes such as situational attributions and appraisals in addition to explicitly described emotions, the ratings are reflective of both internally felt and externally displayed emotion, circumventing issues surrounding emotional self-reports and the difficulty in accurately labeling one's emotions (Larsen and Fredrickson, 1999). As a result, the ratings of information relevant to emotional expression were interpreted as a 
representation of emotional experience. Interrater agreement $\left(\mathrm{r}_{\mathrm{wg}}{ }^{*}\right)$ was .89 for anger and .73 for guilt.

Social behaviors. Social behaviors in the participants' responses were also rated by a fiveitem scale developed for this study that was derived from the reparative behaviors discussed in the guilt literature (e.g. Tangney, 1995) and externalization of blame from the anger literature (e.g. Lerner and Tiedens, 2006). Apologizing, accepting responsibility, making excuses, shifting blame and promising to work harder in the future were rated on five-point Likert scales ( $1=$ 'Not at all', $5=$ 'Great extent'). Interrater agreement for these items ranged from .71 to .90 . A confirmatory maximum likelihood estimation (MLE) resulted in two eigenvalues greater than 1 (factor $1=2.69$, factor $2=1.17$ ) and supported the two-factor structure, $\chi^{2}(4, N=260)=13.55, p=.009$; Comparative Fit Index $(\mathrm{CFI})=.98$; Tucker Lewis Index $(\mathrm{TLI})=.96$; and Root Mean Square Error of Approximation (RMSEA) $=.096, \mathrm{CI}_{.90}[.043, .155]$. These components were therefore labeled as positive social behaviors and negative social behaviors, and the three- and two-item subscales were each averaged. Cronbach's $\alpha$ of the positive scale was .82 and .74 for the negative scale.

Task performance. After responding to the failure feedback, participants were asked to complete a restaurant design and marketing plan in an email sent by Mark, the negative feedback provider. The instructions gave some suggestions for details to include (e.g. restaurant theme, target market) but were vague enough to allow for a range of creative responses. We chose this task because undergraduates are familiar with the topic, tasks in the business domain are typically seen as relevant and interesting by undergraduates (Marcy and Mumford, 2007) and similar marketing tasks have been viable in prior research (Marcy and Mumford, 2007; Vessey et al., 2011). Responses were rated on a five-point Likert scale ( 1 = Poor, 5 = Excellent) for quality, originality and elegance (Vessey et al., 2011) by the same three raters as the emotional reaction and social behavior scales. Overall quality was defined as the completeness, coherence and usefulness of the proposed solution. Originality was the novelty of the plan in terms of unexpectedness and elaboration. The plan's elegance was the degree to which it was effective while maintaining simplicity with respect to refinement, cleverness and flow of articulation. Interrater agreement for quality, originality and elegance were $.89, .84$ and .85, respectively.

Evaluations of feedback source. Impressions of the competence and likeability of the peer or supervisor who provided feedback were measured with 16 self-report items. These are two evaluations commonly made in social settings (Fiske et al., 2007), including of message sources (Chaiken and Eagly, 1983). The seven competency items were based on the source's ability to perform, expertise and communication skills, and the nine likeability items were based on the source being approachable and likeable and the possibility of being friends or cooperating with the source in the future (Chaiken and Eagly, 1983; Lewis, 2000). Items were contextualized for workplace interactions, and participants were asked to rate the feedback provider on five-point Likert scales of agreement, frequency or level. The internal reliability coefficient for competence was .89 and .91 for likeability. 


\section{Covariates}

Propensity for guilt and shame. Guilt and shame are both common responses to a personal failure or transgression, can impact consequential social behaviors and are linked to anger experiences (Tangney, 1995). Therefore, the 16-item Test of Self-Conscious Affect - Version 3 (TOSCA-3; Tangney et al., 2000) was used to assess general likeliness of guilt and shame via reactions to scenarios using a five-point Likert scale ranging from 1 (Not likely) to 5 (Very likely). Cronbach's $\alpha$ was .71 for guilt and .72 for shame.

Self-esteem. Self-esteem may lead individuals to react differentially to feedback and make attributions about external factors such as qualities or characteristics of the feedback source (Audia and Locke, 2003; Ilgen et al., 1979). Therefore, the self-esteem of participants was measured using the 10-item Rosenberg Self-Esteem Scale (Rosenberg, 1965) with a four-point Likert scale ranging from 1 (Strongly disagree) to 4 (Strongly agree) $(\alpha=.90)$.

Demographics. Twelve demographic items were given to measure age, gender, ethnicity, major, year in school, and experience in marketing and advertising. Gender was of particular importance because it is related to trait experience of self-conscious emotions (Else-Quest et al., 2012) and creative performance (Vessey et al., 2011).

\section{Results}

Descriptive statistics and intercorrelations among study variables are presented in Tables 1 through 3. All analyses controlled for guilt- and shame-proneness and gender. Trait anger was tested but removed as it was not correlated with the outcomes or significant in any analyses. Additional covariates were included in analyses for evaluations of the feedback source (i.e. self-esteem) and creative performance (i.e. number of solutions - intelligence was tested but excluded owing to non-significance). All direct effects were tested using one-way between-group ANCOVAs (Analysis of Covariance), and all mediational analyses were conducted using a MEDIATE SPSS Macro (Hayes and Preacher, in press), employing 5000 bootstrapped resamples to test the model (example in Figure 1). This allows comparison of multicategorical independent variables with multiple mediators and covariates, and, for this study, the neutral emotional display conditions were set as the reference group. Significant mediational effects resulted if the 95 percent confidence interval $\left(\mathrm{CI}_{.95}\right)$ of the indirect effect does not contain zero. No pattern or magnitude of interpretations changed for the ANCOVAs when all covariates were excluded, but multiple indirect effects previously non-significant with covariates appeared, indicating that the covariates might have been reducing Type I errors and were therefore kept in the analyses.

\section{Manipulation checks}

All manipulation checks were successful. A multiple choice item was given to assess Mark's emotional display, and a chi-square test of independence indicated a significant 


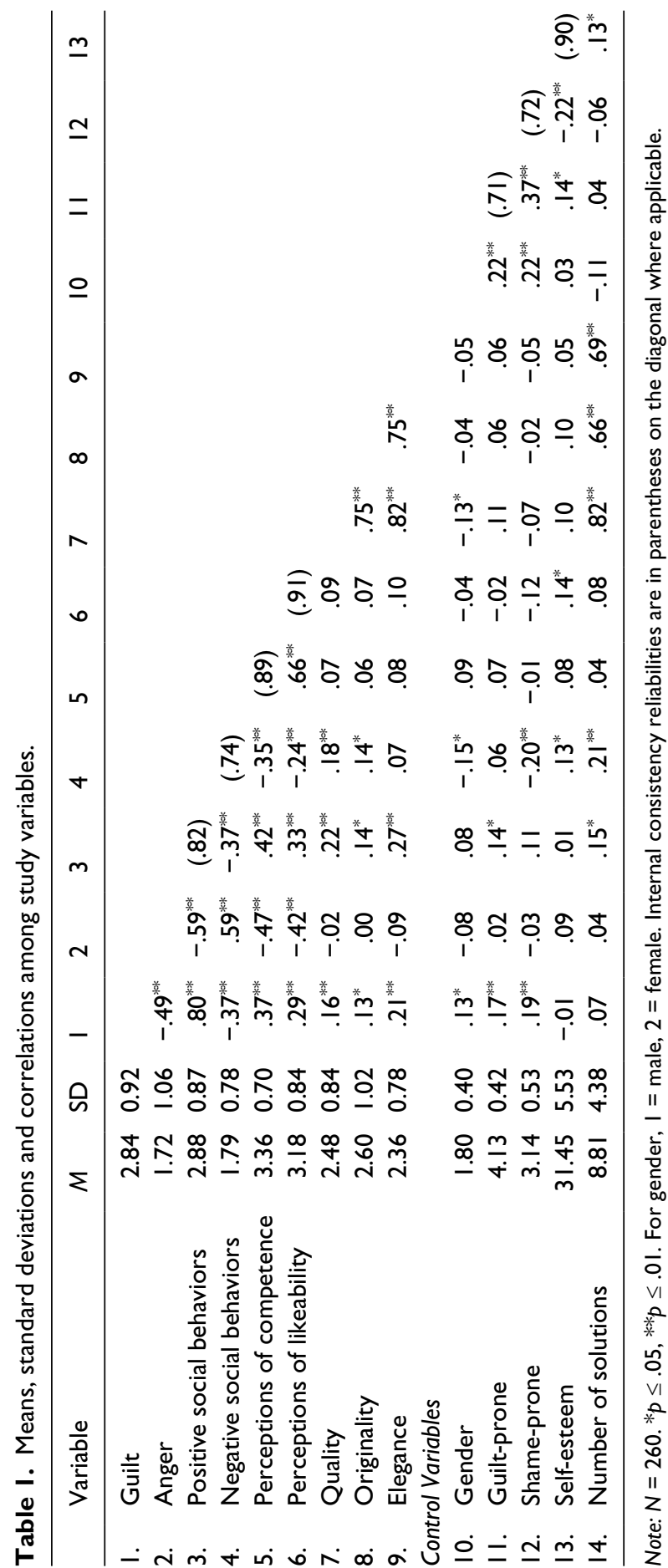




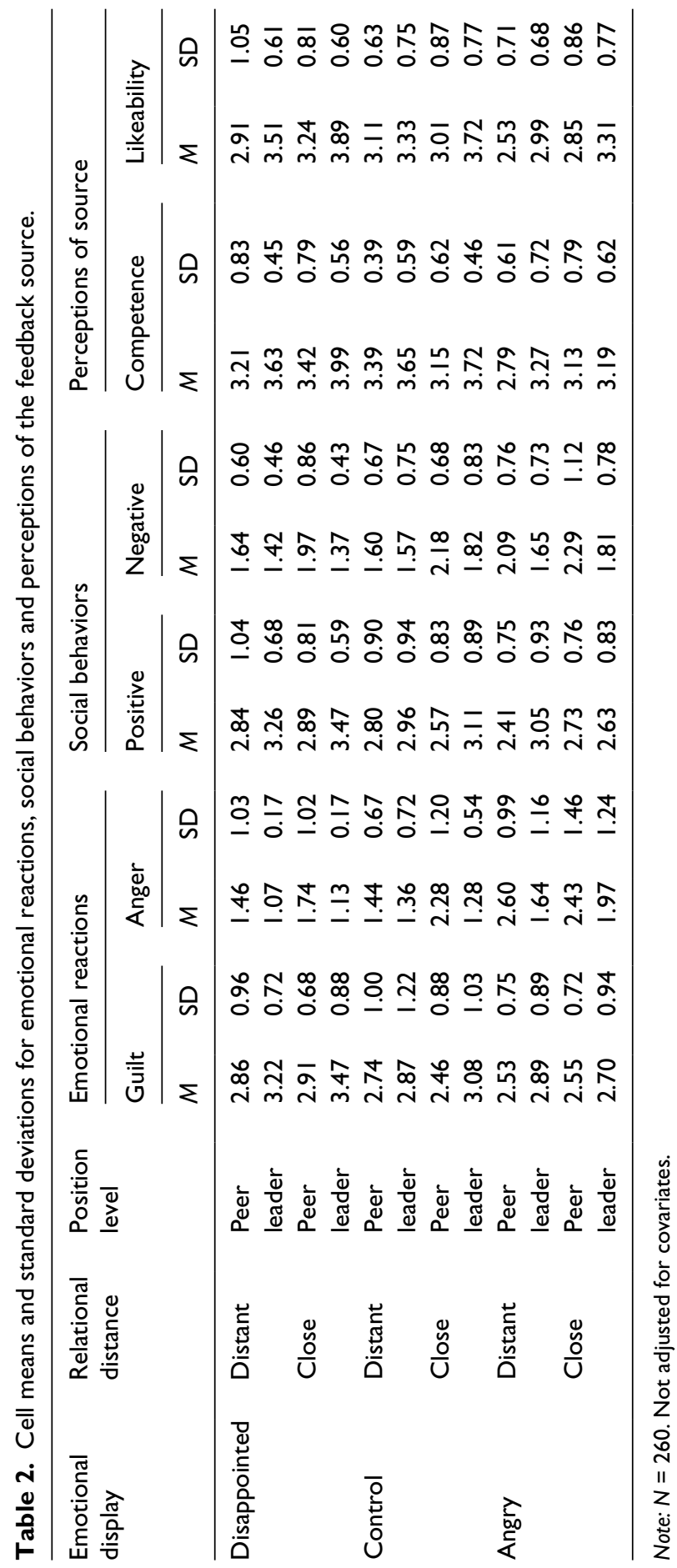


Table 3. Cell means and standard deviations for task performance.

\begin{tabular}{|c|c|c|c|c|c|c|c|c|}
\hline \multirow{3}{*}{$\begin{array}{l}\text { Emotional } \\
\text { display }\end{array}$} & \multirow{3}{*}{$\begin{array}{l}\text { Relational } \\
\text { distance }\end{array}$} & \multirow{3}{*}{$\begin{array}{l}\text { Position } \\
\text { level }\end{array}$} & \multicolumn{6}{|c|}{ Task performance } \\
\hline & & & \multicolumn{2}{|c|}{ Quality } & \multicolumn{2}{|c|}{ Originality } & \multicolumn{2}{|c|}{ Elegance } \\
\hline & & & $M$ & SD & $M$ & SD & $M$ & SD \\
\hline \multirow[t]{4}{*}{ Disappointed } & Distant & Peer & 2.28 & 1.00 & 2.57 & 1.14 & 2.17 & 1.07 \\
\hline & & leader & 2.48 & 0.62 & 2.53 & 0.81 & 2.46 & 0.66 \\
\hline & Close & Peer & 2.58 & 0.84 & 2.64 & 0.96 & 2.38 & 0.81 \\
\hline & & leader & 2.59 & 0.70 & 2.66 & 1.12 & 2.39 & 0.76 \\
\hline \multirow[t]{4}{*}{ Control } & Distant & Peer & 2.19 & 0.81 & 2.47 & 1.02 & 2.10 & 0.79 \\
\hline & & leader & 2.61 & 0.93 & 2.58 & 1.19 & 2.39 & 0.70 \\
\hline & Close & Peer & 2.64 & 1.03 & 2.70 & 1.18 & 2.49 & 0.97 \\
\hline & & leader & 2.46 & 1.01 & 2.79 & 1.17 & 2.37 & 0.83 \\
\hline \multirow[t]{4}{*}{ Angry } & Distant & Peer & 2.56 & 0.83 & 2.60 & 1.02 & 2.39 & 0.78 \\
\hline & & leader & 2.55 & 0.82 & 2.71 & 1.03 & 2.58 & 0.67 \\
\hline & Close & Peer & 2.35 & 0.66 & 2.75 & 0.95 & 2.30 & 0.58 \\
\hline & & leader & 2.51 & 0.83 & 2.29 & 0.75 & 2.33 & 0.58 \\
\hline
\end{tabular}

Note: $N=260$. Not adjusted for covariates.

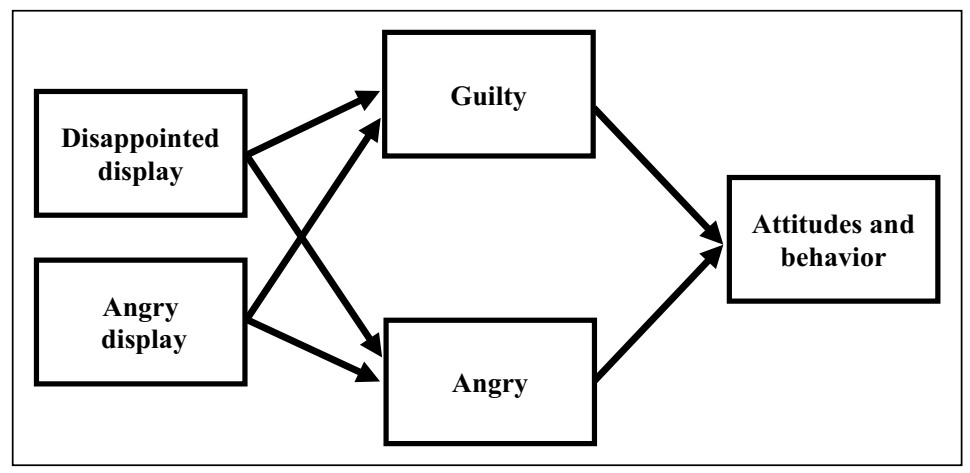

Figure I. Example model of mediational analyses conducted. Covariates are not pictured but are included in analyses.

relationship between the type of emotion displayed and perceived in the expected manner, $\left.\chi^{2}(8, N=259)=130.26, p \leq .001\right)$. Two five-point Likert scale items regarding emotional display ( $1=$ 'Not at all', $5=$ 'Great extent') also showed that participants in the angry conditions perceived Mark as more angry $(M=4.29, \mathrm{SD}=1.15)$ than participants in the disappointed $(M=2.73, \mathrm{SD}=.98)$ and control conditions $(M=2.67, \mathrm{SD}=$ $.90), F(2,251)=72.47, p \leq .001$. Bonferonni post hocs indicated angry conditions were significantly higher than both disappointed and control $(p \leq .001)$. The disappointed conditions also perceived Mark as expressing significantly more disappointment $(M=$ $4.46, \mathrm{SD}=1.01)$ than the angry $(M=3.91, \mathrm{SD}=1.25)$ and control conditions $(M=3.93$, 
$\mathrm{SD}=1.24), F(2,251)=6.06, p \leq .01$, Bonferroni post hocs $p \leq .01$. In addition, the salience of the emotional manipulation, as opposed to cognitive factors, was evaluated by six $\mathrm{PhD}$-level students blind to the conditions and purposes of the study. Responses indicated that the most salient and influential aspects were the emotional components in the feedback emails (the control email appeared neutral), and immediate reactions centered on affective reactions and recognition of having violated a norm of performing adequately in the workplace. The raters also listed and rated any emotions visible in the prompt on a 1-5 scale. The disappointed email had the highest mean for disappointment (4.80), the angry prompt had the highest mean for anger (5.00) and the control prompt had low means for both disappointment (2.80) and anger (1.00).

The perception of the closeness of the relationship was rated on two items with a fivepoint Likert scale ( $1=$ Strongly disagree, $5=$ Strongly agree). Participants in the close conditions had significantly higher mean responses for perceived closeness $(M=3.46$, $\mathrm{SD}=1.10)$ than those in the distant conditions $(M=1.92, \mathrm{SD}=.88), t(258)=-12.40, p$ $\leq .001$. A chi-square test of independence also confirmed an expected relationship between the manipulated and perceived position level of the source, $\chi^{2}(3,260)=125.10$, $p \leq .001$, such that 90 percent of those in the leader conditions and 73 percent of those in the coworker conditions answered correctly.

\section{Feedback emotions}

Feeling angry was found to be significantly different across the emotional display conditions, $F(2,245)=17.34, p \leq .001, \eta_{\mathrm{p}}{ }^{2}=.12$. Using Bonferroni post hoc comparisons, those whose feedback was given in an angry manner experienced significantly higher levels of anger $(M=2.18, \mathrm{SE}=.10)$ than those who received feedback in a neutral $(M=$ $1.58, \mathrm{SE}=.11), p \leq .001$, or disappointed manner $(M=1.34, \mathrm{SE}=.11), p \leq .001$, supporting Hypothesis 1a. In this analysis, the disappointed and control conditions were not significantly different. The levels of experienced guilt were also significantly different across conditions, $F(2,245)=7.27, p \leq .001, \eta_{\mathrm{p}}{ }^{2}=.06$. Bonferroni post hoc tests indicated that those who received feedback with a disappointed emotional display $(M=3.14$, $\mathrm{SE}=.10)$ experienced higher levels of guilt than those who received feedback with a neutral display $(M=2.80, \mathrm{SE}=.10), p \leq .05$, or an angry display $(M=2.64, \mathrm{SE}=.09), p$ $\leq .001$, supporting Hypothesis $1 \mathrm{~b}$. The neutral and angry conditions' levels of guilt were not significantly different.

As was anticipated, a main effect was found for emotional display on positive social behaviors, $F(2,245)=6.34, p \leq .01, \eta_{\mathrm{p}}{ }^{2}=.05$. Overall, in support of Hypothesis $2 \mathrm{a}$, those in the disappointed conditions $(M=3.13, \mathrm{SE}=.09)$ made more attempts at repairing the situation than those in the angry conditions $(M=2.69, \mathrm{SE}=.09), p \leq .001$. The neutral conditions' frequency of such behaviors were between the other two conditions' $(M=$ $2.86, \mathrm{SE}=.09)$ but were not significantly different from either. Negative social behaviors were also less frequent for those in the disappointed conditions $(M=1.60, \mathrm{SE}=.08)$ than for participants in the angry display conditions $(M=1.99, \mathrm{SE}=.08), F(2,244)=6.74, p$ $\leq .001, \eta_{\mathrm{p}}{ }^{2}=.05$, Bonferroni post hoc $p \leq .001$. Again, participants in the control conditions demonstrated such negative behaviors at a frequency between the other two display types $(M=1.76, \mathrm{SE}=.08)$ but were not significantly different. The mediational hypothesis (H2b) was largely supported (Table 4$)$. The relationship between emotional display 
and positive social behaviors were mediated by feelings of guilt following a disappointed display $\left(\mathrm{CI}_{.95}=.045, .389\right)$ and anger following an angry display $\left(\mathrm{CI}_{.95}=-.221,-.062\right)$. Negative social behaviors were explained by angry reactions to an anger display $\left(\mathrm{CI}_{.95}=\right.$ $.095, .405)$ but not guilty reactions to a disappointed display $\left(\mathrm{CI}_{.95}=-.079, .004\right)$.

With respect to Hypothesis 3a, comparison across the three emotional display conditions revealed a significant main effect on perceptions of the competency of the feedback source, $F(2,244)=14.16, p \leq .001, \eta_{\mathrm{p}}{ }^{2}=.10$. Participants thought most highly of the feedback provider's competence when they displayed disappointment $(M=3.57, \mathrm{SE}=$ $.07)$ versus no emotion $(M=3.48, \mathrm{SE}=.07)$ or anger $(M=3.09, \mathrm{SE}=.07)$. Bonferroni post hocs indicated that the results were driven by significant differences between disappointed and angry displays $(p \leq .001)$ and angry and neutral displays $(p \leq .001)$. A similar pattern was found for likeability of the source, $F(2,244)=8.44, p \leq .001, \eta_{\mathrm{p}}{ }^{2}=.07$, such that the disappointed feedback source was seen as significantly more likeable $(M=3.39$, $\mathrm{SE}=.08)$ than angry sources $(M=2.93, \mathrm{SE}=.08), p \leq .001$, lending support to Hypothesis 3a. Angry sources were also perceived as significantly less likeable than emotionally neutral feedback providers $(M=3.28, \mathrm{SE}=.08), p \leq .01$. Mediational analyses also found support for Hypothesis $3 \mathrm{~b}$, as seen in Table 4. Competence of the feedback sources who displayed disappointment was higher as a result of guilty reactions $\left(\mathrm{CI}_{.95}=.007\right.$, $.110)$ and lower for those who displayed anger owing to angry reactions $\left(\mathrm{CI}_{.95}=-.233\right.$, -.059) (partially mediated). Results reflected a similar pattern for likeability with both guilt $\left(\mathrm{CI}_{.95}=.001, .125\right)$ and anger $\left(\mathrm{CI}_{.95}=-.295,-.070\right)$ as full mediators.

The direct effect of emotional display was independently assessed for quality, originality, and elegance (QOE), all of which were not significant, leading us to reject Hypothesis 4a. However, mediational analyses did find some indirect effects on performance, lending partial support to Hypothesis $4 \mathrm{~b}$ (see Table 4). Although no mediational effects were found for originality, quality was positively affected following a disappointed display owing to guilty emotional reactions $\left(\mathrm{CI}_{.95}=.005, .091\right)$, as was elegance $\left(\mathrm{CI}_{.95}=.005, .110\right)$. Elegance was also affected following interactions with an angry feedback source as reactions of anger partially explained the detrimental performance on the follow-up task $\left(\mathrm{CI}_{.95}=-.099,-.001\right)$.

\section{Interactions}

Exploratory interactions were also proposed, which asked how contextual factors might interact with emotional displays to influence attitudes and behavior. No significant interactions occurred, implicating the salience of the emotional display regardless of its source.

\section{Discussion}

By examining the EASI in a new context, informal feedback, this study extends research on emotions in the workplace in several ways. Overall, these findings support the idea that social behaviors and evaluations in organizations operate differently in response to different negative emotional displays, partially owing to emotional reactions (Van Kleef, 2009). Although both displays were negatively valenced, anger prompted reciprocal 
Table 4. Mediational effects with corresponding bootstrap confidence intervals for attitudes and behavior.

\begin{tabular}{|c|c|c|c|c|c|}
\hline $\begin{array}{l}\text { Dependent } \\
\text { variable }\end{array}$ & Mediator & $\begin{array}{l}\text { Emotional } \\
\text { display }\end{array}$ & $\begin{array}{l}\text { Indirect } \\
\text { effect }\end{array}$ & SE & $95 \% \mathrm{Cl}$ \\
\hline Positive social & Guilt & & & & \\
\hline \multirow[t]{5}{*}{ behaviors } & & Disappointed & .22 & .09 & {$[.045, .389]$} \\
\hline & & Angry & -.10 & .09 & {$[-.269, .081]$} \\
\hline & Anger & & & & \\
\hline & & Disappointed & .05 & .03 & {$[-.002, .123]$} \\
\hline & & Angry & -.13 & .04 & {$[-.221,-.062]$} \\
\hline Negative social & Guilt & & & & \\
\hline \multirow[t]{5}{*}{ behaviors } & & Disappointed & -.02 & .02 & {$[-.079, .004]$} \\
\hline & & Angry & .01 & .01 & {$[-.005, .052]$} \\
\hline & Anger & & & & \\
\hline & & Disappointed & -.09 & .05 & {$[-.201, .004]$} \\
\hline & & Angry & .23 & .08 & {$[.095, .405]$} \\
\hline \multirow[t]{6}{*}{ Competence } & Guilt & & & & \\
\hline & & Disappointed & .04 & .03 & {$[.007, .110]$} \\
\hline & & Angry & -.02 & .02 & {$[-.072, .013]$} \\
\hline & Anger & & & & \\
\hline & & Disappointed & .05 & .03 & {$[-.001, .125]$} \\
\hline & & Angry ${ }^{+}$ & -.13 & .04 & {$[-.233,-.059]$} \\
\hline \multirow[t]{6}{*}{ Likeability } & Guilt & & & & \\
\hline & & Disappointed & .04 & .03 & {$[.001, .125]$} \\
\hline & & Angry & -.02 & .02 & {$[-.076, .008]$} \\
\hline & Anger & & & & \\
\hline & & Disappointed & .07 & .04 & {$[-.004, .152]$} \\
\hline & & Angry & -.16 & .06 & {$[-.295,-.070]$} \\
\hline \multirow[t]{6}{*}{ Quality } & Guilt & & & & \\
\hline & & Disappointed & .03 & .02 & {$[.005, .091]$} \\
\hline & & Angry & -.01 & .02 & {$[-.055, .009]$} \\
\hline & Anger & & & & \\
\hline & & Disappointed & .01 & .01 & {$[-.006, .031]$} \\
\hline & & Angry & -.01 & .02 & {$[-.055, .023]$} \\
\hline \multirow[t]{6}{*}{ Originality } & Guilt & & & & \\
\hline & & Disappointed & .03 & .03 & {$[-.002, .112]$} \\
\hline & & Angry & -.01 & .02 & {$[-.076, .008]$} \\
\hline & Anger & & & & \\
\hline & & Disappointed & -.00 & .02 & {$[-.049, .018]$} \\
\hline & & Angry & .01 & .03 & {$[-.048, .087]$} \\
\hline \multirow[t]{6}{*}{ Elegance } & Guilt & & & & \\
\hline & & Disappointed & .04 & .03 & {$[.005, .110]$} \\
\hline & & Angry & -.02 & .02 & {$[-.062, .01 \mathrm{I}]$} \\
\hline & Anger & & & & \\
\hline & & Disappointed & .02 & .01 & {$[-.001, .055]$} \\
\hline & & Angry $^{+}$ & -.04 & .02 & {$[-.099,-.001]$} \\
\hline
\end{tabular}

Note: ${ }^{+}$denotes partial mediation. All indirect effects are bias corrected and relative to the control group. $\mathrm{SE}=$ standard error. 
anger, while disappointment prompted complementary guilt, and the outcomes that followed guilt were generally more beneficial to organizational and interpersonal factors than anger. As a result, this study has helped elucidate some stipulations under which feedback does and does not work, which researchers have been investigating since Kluger and DeNisi's (1996) feedback intervention meta-analysis. Therefore, understanding feedback recipient reactions and being able to use the EASI model to predict specific action tendencies linked to discrete emotions could have important implications for how to deliver effective feedback within the workplace.

Interpersonal reparative behaviors linked with emotional display and experiences have not been considered often in the workplace, but they appear to be common and important responses in a feedback context. The ability for disappointment to evoke positive social behaviors via guilt is especially important following feedback, since it is beneficial to both organizations and the people in them for individuals to take responsibility for their mistakes as opposed to blaming others. Disappointment may communicate belief in an employee's abilities, while anger may be more interpersonally hurtful. Hareli and Hess (2008) wrote that the cause of anger is partially the degree of damage inflicted by another - the more hurtful the message, the higher the elicitation of anger. Therefore, those who received feedback in an angry manner may have taken offense and retaliated by blaming the source or making other excuses. The common endless excuses following destructive feedback also follow this reasoning (Baron, 1988), and such excuses and external attributions are also common methods for minimizing negative emotions (Baumeister et al., 1994). The relatively lower levels of threat associated with disappointment may also explain the more positive evaluations of the feedback source. Those feeling higher levels of guilt usually assess their behavior and focus attention on how their own actions fell short. Those who become angry, on the other hand, may think others are to blame and, as a result, the feedback is not seen as accurate, justified or fair. This may lead them to minimize the message and view the source as incompetent and unlikeable in order to protect their own self-esteem and character.

Supervisors and coworkers alike can benefit from applying these findings, especially if trying to maintain productive working relationships with feedback recipients. Maintaining such relationships are noteworthy as research has found that fostering positive relationships can have impacts over time on critical organizational outcomes such as performance, job satisfaction and citizenship behaviors (Schyns and Day, 2010). Moreover, the workplace is becoming more dependent on teams and collaboration (Kozlowski and Bell, 2003), and informal feedback may continually come from our peers owing to increases in the use of processes such as self-managed work groups where leadership functions, such as feedback provision, are shared. Social-functional frameworks have commonly focused on such interpersonal variables while wholly ignoring cognitive factors such as performance. One of this study's most powerful findings is that emotional displays did not have a direct effect on creative performance but did have some indirect effects through emotional reactions, extending past research on affect in creativity (De Dreu et al., 2012). The emotional reactions may have provided an additional source of feedback information regarding their performance, inducing different levels of future performance. Since the main goal of feedback is to improve performance, this finding speaks to the critical nature of emotions in basic workplace functions central 
to an organization's success, such as feedback and performance. This idea is supported when considering the means for the neutral emotionality groups. Although they were not significantly different from angry or disappointed groups, they were lowest in all analyses for creative performance, suggesting that some sort of emotion is better than none because they help individuals interpret or make sense of the ambiguity of social interactions (Van Kleef et al., 2010).

In addition, informal feedback and the nature of the sources from which it can come have not been considered in tandem with emotional displays, and our findings demonstrate that contextual factors regarding the feedback source did not seem to moderate the impact of the emotions displayed during feedback provision on performance or other outcomes. This underscores the idea that emotions have common properties and communicate similar messages across situations and contexts, providing a compelling reason for greater consideration of the impacts of emotional displays in feedback situations.

\section{Limitations and future research}

Although this study extends previous research and practice, it has some limitations. First, the experimental design used a low-fidelity simulation instead of having participants receive feedback on a task they actually completed. However, over 98 percent of the participants in this study indicated that the situations were realistic and believable, and past research has also had success in providing simulated organizational informal feedback (e.g. Fedor et al., 1989) and asking participants to become members of fictional organizations and understand emotional interactions via written scenarios (Connelly and Ruark, 2010). In addition, samples drawn from similar populations have typically had at least some work experience (Vessey et al., 2011), with averages of two to three years (Connelly and Ruark, 2010; Gaddis et al., 2004). In this particular sample, 34 percent had prior experience working in a restaurant, where informal feedback is likely to occur from managers and coworkers alike on a frequent basis. Many students are also now oftentimes enrolled in online courses in which they receive feedback via email from both professors and virtual teammates, factors that may also ease translation into understanding a workplace setting and feedback. Even though the participants were capable of understanding the context, however, it is unclear how generalizable these results are to the workplace. Results may be even stronger in an actual work setting, especially for task performance.

The simulation and interpretation of emotional displays in feedback also have some limitations. Emotional displays might have a stronger effect if feedback were given in person, as visible facial expressions provide strong cues to others (Ekman and Friesen, 1969) and individuals in physical organizations could arguably feel their reactive emotions even more deeply owing to investment in their jobs and work performance. The interactions between these emotional displays and relational factors may also be stronger in a field study where relationships are more personal and where a larger sample size may be available to provide additional power to test for interactions. The emotional reactions found in this study may also be emotional displays participants are willing to show as opposed to genuinely experienced emotions, but both the alternative 
manipulation check and the low levels of other emotions coded by the raters demonstrate that the emotional manipulations were at least somewhat successful. Moreover, the interpretation of these affective stimuli as driving the responses to failure feedback may be a biased one owing to the study's purpose, and other explanations via cognitive factors may be important to consider. We also cannot be completely certain that informal feedback functions the same in an online versus a face-to-face context. However, research in other areas involving feedback, such as training, has suggested that online and in-person communications can be equally effective as long as the content stays consistent (Salas et al., 2012). The success of our manipulations also suggests that at least some overlap occurs between online and face-to-face feedback, even when emotionally laden, and more research is needed to fully understand this relationship. As a result, we believe these limitations do not diminish the value of the findings, as an experiment serves to tease out the effects of manipulations that may not be feasible in a complex field setting.

Future research could also consider other theories that may play into emotions and failure feedback. For instance, the justice literature implies that those who stay calm (i.e. not angry) might have messages/feedback that seem more fair, which is an important part of accepting feedback. Negative feedback message constructiveness has been linked to various types of organizational justice, and such perceptions of fairness have important implications for organizational relationships and employee responses, including performance (Chory and Westerman, 2009). In addition, perceptions of distributive and procedural justice can play a role in inducing specific affective reactions (Weiss et al., 1999), and cognitive attributions made regarding justice in feedback, including the emotional display, may help explain the emotional reactions. How one copes with negative emotional displays in failure feedback (e.g. problem- or emotionfocused coping responses; Folkman and Lazarus, 1980), especially when the emotions are directed at oneself, could also impact the social-functional properties of negative emotions. For instance, those who are more problem focused may be inclined to engage in reparative behaviors, while those who rely more on emotion-focused strategies may have avoided the situation by making excuses to deal with their feelings of inefficacy. Individual difference tendencies to cope via either method could be considered to develop possible interventions aimed at improving such strategies following failure feedback.

Follow-up studies could also expand the number and type of discrete emotional displays included, and a study using both positive and negative emotions with failure feedback might help disentangle their effects. Their impact on other performance domains could also be considered (Visser et al., 2013), including over longer time periods. Overall, reflection on the very distinct emotional and behavioral reactions found in our study underscores to the need to consider the different action tendencies following emotional experiences in the workplace, especially asymmetrical effects such as the benefits of disappointment and the downfalls of anger. Emotions offer a fruitful area in understanding reactions to failure feedback, and acknowledging the negative emotions inherent in these situations can help supervisors and coworkers alike provide more effective, impactful feedback. 


\section{Appendix: Emails for disappointed, angry and control failure feedback \\ Disappointed failure feedback}

From : Mark Turner $<$ mturner@epicure.com>

To : Jordan Gilmore <jgilmore@epicure.com>

\section{Subject : Zeager Project Update}

Jordan,

We heard back from the client on the Zeager Corp project, and they told us it was of such poor quality that they no longer wanted to work with Epi-Cure. I am extremely disappointed that you turned in a project with so many mistakes and other signs of carelessness. I was expecting so much more from you on this assignment. You really let me down, Jordan.

Sincerely,

Mark

[You can almost hear the disappointment in his voice as you read his email.]

\section{Angry failure feedback}

From : Mark Turner <mturner@epicure.com>

To : Jordan Gilmore <jgilmore@epicure.com>

\section{Subject : Zeager Project Update}

Jordan,

We heard back from the client on the Zeager Corp project, and they told us it was so bad that they refuse to work with Epi-Cure anymore. I CANNOT believe you turned in a project with so many mistakes and other signs of total, complete, and utter LAZINESS!! Apparently, it was too much to ask for even minimally acceptable performance on your part of this assignment. You blew it, Jordan!

Mark

[You can hear the anger in his voice as you read his email.]

\section{Control failure feedback}

From : Mark Turner <mturner@epicure.com>

To : Jordan Gilmore <jgilmore@epicure.com>

\section{Subject : Zeager Project Update}

Jordan,

We heard back from the client on the Zeager Corp project, and they told us it was of such poor quality that they no longer wanted to work with Epi-Cure. There were just too many mistakes. The results are highly unsatisfactory, Jordan.

Sincerely,

Mark 


\section{Acknowledgement}

We would like to thank Jennifer Griffith, Olivia Cooper and James Johnson for their contributions to the present effort. We would also like to express appreciation for the helpful comments we received from three anonymous reviewers.

\section{Funding}

This research received no specific grant from any funding agency in the public, commercial, or not-for-profit sectors.

\section{References}

Ashkanasy NM and Humphrey RH (2011) Current emotion research in organizational behavior. Emotion Review 3(2): 214-224.

Audia PG and Locke EA (2003) Benefiting from negative feedback. Human Resource Management Review 13(4): 631-646.

Baker N (2010) Employee feedback technologies in the human performance system. Human Resource Development International 13(4): 477-485.

Barclay LJ, Skarlicki DP and Pugh S (2005) Exploring the role of emotions in injustice perceptions and retaliation. Journal of Applied Psychology 90(4): 629-643.

Baron RA (1988) Negative effects of destructive criticism: Impact on conflict, self-efficacy, and task performance. Journal of Applied Psychology 73: 199-207.

Baumeister RF, Stillwell AM and Heatherton TF (1994) Guilt: An interpersonal approach. Psychological Bulletin 115(2): 243-267.

Brief AP and Weiss HM (2002) Organizational behavior: Affect in the workplace. Annual Review of Psychology 53(1): 279-307.

Chaiken S and Eagly AH (1983) Communication modality as a determinant of persuasion: The role of communicator salience. Journal of Personality and Social Psychology 45(2): 241-256.

Chory RM and Westerman C (2009) Feedback and fairness: The relationship between negative performance feedback and organizational justice. Western Journal of Communication 73(2): $157-181$.

Connelly S and Ruark G (2010) Leadership style and activating potential moderators of the relationships among leader emotional displays and outcomes. The Leadership Quarterly 21(5): 745-764.

De Dreu CW, Baas M and Nijstad BA (2012) The emotive roots of creativity: Basic and applied issues on affect and motivation. In: Mumford MD (ed.) Handbook of Organizational Creativity. London: Academic Press, 217-240.

Dunn JR and Schweitzer ME (2005) Feeling and believing: The influence of emotion on trust. Journal of Personality and Social Psychology 88(5): 736-748.

Ekman P and Friesen WV (1969) Nonverbal leakage and clues to deception. Psychiatry: Journal for the Study of Interpersonal Processes 32(1): 88-106.

Elfenbein H (2007) Emotion in organizations: A review and theoretical integration. The Academy of Management Annals 1(1): 315-386.

Else-Quest NM, Higgins A, Allison C and Morton LC (2012) Gender differences in self-conscious emotional experience: A meta-analysis. Psychological Bulletin 138(5): 947-981.

Fedor DB, Eder RW and Buckley M (1989) The contributory effects of supervisor intentions on subordinate feedback responses. Organizational Behavior and Human Decision Processes 44(3): 396-414.

Ferguson TJ, Olthof T and Stegge H (1997) Temporal dynamics of guilt: Changes in the role of interpersonal and intrapsychic factors. European Journal of Social Psychology 27(6): 659673. 
Fischer AH and Manstead ASR (2008) Social functions of emotion. In: Lewis M, Haviland-Jones JM and Barrett L (eds) Handbook of Emotions, 3rd edn. New York,: Guilford Press, 456-468.

Fischer AH and Roseman I (2007) Beat them or ban them: The characteristics and social functions of anger and contempt. Journal of Personality and Social Psychology 93(1): 103-115.

Fiske ST, Cuddy AC and Glick P (2007) Universal dimensions of social cognition: Warmth and competence. Trends in Cognitive Sciences 11(2): 77-83.

Fitness J (2000) Anger in the workplace: An emotion script approach to anger episodes between workers and their superiors, co-workers and subordinates. Journal of Organizational Behavior 21(2): 147-162.

Folkman S and Lazarus RA (1980) An analysis of coping in a middle-aged community sample. Journal of Health and Social Behavior 21(3): 219-239.

Gaddis B, Connelly S and Mumford MD (2004) Failure feedback as an affective event: Influences of leader affect on subordinate attitudes and performance. The Leadership Quarterly 15(5): 663-686.

Gibson DE and Callister R (2010) Anger in organizations: Review and integration. Journal of Management 36(1): 66-93.

Gibson DE and Schroeder SJ (2002) Grinning, frowning, and emotionless: Agent perceptions of power and their effects on felt and displayed emotions in influence attempts. In: Ashkanasy NM, Zerbe WJ and Hartel CEJ (eds) Managing Emotions in the Workplace. New York: Sharpe, 184-211.

Gruenewald TL, Dickerson SS and Kemeny ME (2007) A social function for self-conscious emotions: The social self preservation theory. In: Tracy JL, Robins RW and Tangney J (eds) The Self-Conscious Emotions: Theory and Research. New York: Guilford Press, 68-87.

Hareli S and Hess U (2008) The role of causal attribution in hurt feelings and related social emotions elicited in reaction to other's feedback about failure. Cognition and Emotion 22(5): 862-880.

Hayes AF and Preacher KJ (in press) Statistical mediation analysis with a multicategorical independent variable. British Journal of Mathematical and Statistical Psychology.

Herold DM, Liden RC and Leatherwood ML (1987) Using multiple attributes to assess sources of performance feedback. Academy of Management Journal 30(4): 826-835.

Ilgen DR and Davis CA (2000) Bearing bad news: Reactions to negative performance feedback. Applied Psychology: An International Review 49(3): 550-565.

Ilgen DR, Fisher CD and Taylor MS (1979) Consequences of individual feedback on behavior in organizations. Journal of Applied Psychology 64(4): 349-371.

Ilies R, De Pater IE and Judge T (2007) Differential affective reactions to negative and positive feedback, and the role of self-esteem. Journal of Managerial Psychology 22(6): 590-609.

Kanfer FH, Karoly P and Newman A (1974) Source of feedback, observational learning, and attitude change. Journal of Personality and Social Psychology 29(1): 30-38.

Keltner D and Haidt J (1999) Social functions of emotions at four levels of analysis. Cognition and Emotion 13(5): 505-521.

Ketelaar T and Au W (2003) The effects of feelings of guilt on the behaviour of uncooperative individuals in repeated social bargaining games: An affect-as-information interpretation of the role of emotion in social interaction. Cognition and Emotion 17(3): 429-453.

Kluger AN and DeNisi A (1996) The effects of feedback interventions on performance: A historical review, a meta-analysis, and a preliminary feedback intervention theory. Psychological Bulletin 119(2): 254-284.

Kluger AN, Lewinsohn S and Aiello JR (1994) The influence of feedback on mood: Linear effects on pleasantness and curvilinear effects on arousal. Organizational Behavior and Human Decision Processes 60(2): 276-299. 
Kozlowski S and Bell BS (2003) Work groups and teams in organizations. In: Borman WC, Ilgen DR and Klimoski RJ (eds) Handbook of Psychology, Vol. 12: Industrial and Organizational Psychology. New York: Wiley, 333-375.

Larsen RJ and Fredrickson BL (1999) Measurement issues in emotion research. In: Kahneman D, Diener E and Schwarz N (eds) Well-Being: The Foundations of Hedonic Psychology. New York: Russell Sage Foundation, 40-60.

Lawrence SA (2006) An integrative model of perceived available support, work-family conflict and support mobilisation. Journal of Management and Organization 12(2): 160-178.

Lelieveld G, Van Dijk E, Van Beest I, Steinel W and Van Kleef GA (2011) Disappointed in you, angry about your offer: Distinct negative emotions induce concessions via different mechanisms. Journal of Experimental Social Psychology 47(3): 635-641.

Lelieveld G, Van Dijk E, Van Beest I and Van Kleef GA (2012) Why anger and disappointment affect other's bargaining behavior differently: The moderating role of power and the mediating role of reciprocal and complementary emotions. Personality and Social Psychology Bulletin 38(9): 1209-1221.

Lerner JS and Tiedens LZ (2006) Portrait of the angry decision maker: How appraisal tendencies shape anger's influence on cognition. Journal of Behavioral Decision Making 19(2): $115-137$.

Lewis K (2000) When leaders display emotion: How followers respond to negative emotional expression of male and female leaders. Journal of Organizational Behavior 21(2): 221234.

Lewis M (2008) Self-conscious emotions: Embarrassment, pride, shame, and guilt. In: Lewis M, Haviland-Jones JM and Barrett L (eds) Handbook of Emotions, 3rd edn. New York: Guilford Press, 742-756.

Madlock PE and Booth-Butterfield M (2012) The influence of relational maintenance strategies among coworkers. Journal of Business Communication 49(1): 21-47.

Marcy RT and Mumford MD (2007) Social innovation: Enhancing creative performance through casual analysis. Creativity Research Journal 19(2-3): 123-140.

Neumann R (2000) The causal influences of attributions on emotions: A procedural priming approach. Psychological Science 11(3): 179-182.

Payne SC, Horner MT, Boswell WR, Schroeder AN and Stine-Cheyne KJ (2009) Comparison of online and traditional performance appraisal systems. Journal of Managerial Psychology 24(6): 526-544.

Pulakos ED and O'Leary RS (2011) Why is performance management broken? Industrial and Organizational Psychology: Perspectives on Science and Practice 4(2): 146-164.

Rosenberg M (1965) Society and the Adolescent Self-Image. Princeton, NJ: Princeton University Press.

Saavedra R and Earley P (1991) Choice of task and goal under conditions of general and specific affective inducement. Motivation and Emotion 15(1): 45-65.

Salas E, Tannenbaum SI, Kraiger K and Smith-Jentsch KA (2012) The science of training and development in organizations: What matters in practice. Psychological Science in the Public Interest 13(2): 74-101.

Santra T and Giri VN (2009) Analyzing computer-mediated communication and organizational effectiveness. Review of Communication 9(1): 100-109.

Schwarz N (1990) Feelings as information: Informational and motivational functions of affective states. In: Higgins E and Sorrentino RM (eds) Handbook of Motivation and Cognition: Foundations of Social Behavior, vol. 2. New York: Guilford Press, 527-561.

Schyns B and Day D (2010) Critique and review of leader-member exchange theory: Issues of agreement, consensus, and excellence. European Journal of Work and Organizational Psychology 19(1): 1-29. 
Smith CA and Ellsworth PC (1985) Patterns of cognitive appraisal in emotion. Journal of Personality and Social Psychology 48(4): 813-838.

Sommer K and Baumeister R (1997) Making someone feel guilty: Causes, strategies, and consequences. Aversive Interpersonal Behaviors. New York: Plenum Press, 31-55.

Steelman LA and Rutkowski KA (2004) Moderators of employee reactions to negative feedback. Journal of Managerial Psychology 19(1): 6-18.

Tangney J (1995) Shame and guilt in interpersonal relationships. In: Tangney J and Fischer KW (eds) Self-conscious Emotions: The Psychology of Shame, Guilt, Embarrassment, and Pride. New York: Guilford Press, 114-139.

Tangney JP, Dearing R, Wagner PE and Gramzow R (2000) The Test of Self-Conscious Affect - 3 (TOSCA-3). Fairfax, VA: George Mason University.

Thiel CE, Connelly S and Griffith JA (2012) Leadership and emotion management for complex tasks: Different emotions, different strategies. The Leadership Quarterly 23(3): 517-533.

Tiedens LZ (2001) Anger and advancement versus sadness and subjugation: The effect of negative emotion expressions on social status conferral. Journal of Personality and Social Psychology 80(1): 86-94.

Van Dijk W and Zeelenberg M (2002) What do we talk about when we talk about disappointment? Distinguishing outcome-related disappointment from person-related disappointment. Cognition and Emotion 16(6): 787-807.

Vangelisti AL, Daly JA and Rudnick JR (1991) Making people feel guilty in conversations: Techniques and correlates. Human Communication Research 18(1): 3-39.

Van Kleef GA (2008) Emotion in conflict and negotiation: Introducing the emotions as social information (EASI) model. In: Ashkanasy NM and Cooper CL (eds) Research Companion to Emotion in Organizations. London: Edward Elgar, 392-404.

Van Kleef GA (2009) How emotions regulate social life: The emotions as social information (EASI) model. Current Directions in Psychological Science 18(3): 184-188.

Van Kleef GA and Côté S (2007) Expressing anger in conflict: When it helps and when it hurts. Journal of Applied Psychology 92(6): 1557-1569.

Van Kleef GA, De Dreu CW and Manstead AR (2006) Supplication and appeasement in conflict and negotiation: The interpersonal effects of disappointment, worry, guilt, and regret. Journal of Personality and Social Psychology 91(1): 124-142.

Van Kleef GA, De Dreu CW and Manstead AR (2010) An interpersonal approach to emotion in social decision making: The emotions as social information model. In: Zanna MP (ed.) Advances in Experimental Social Psychology, vol. 42. San Diego, CA: Academic Press, 45-96.

Van Kleef GA, Homan AC, Beersma B, Van Knippenberg D, Van Knippenberg B and Damen F (2009) Searing sentiment or cold calculation? The effects of leader emotional displays on team performance depend on follower epistemic motivation. Academy of Management Journal 52(3): 562-580.

Vessey WB, Barrett J and Mumford MD (2011) Leader cognition under threat: 'Just the Facts'. The Leadership Quarterly 22(4): 710-728

Visser VA, Van Knippenberg D, Van Kleef GA and Wisse B (2013) How leader displays of happiness and sadness influence follower performance: Emotional contagion and creative versus analytical performance. The Leadership Quarterly 24(1): 172-188.

Weiner B (1986) An Attributional Theory of Motivation and Emotion. New York: Springer Verlag.

Weiss HM, Suckow K and Cropanzano R (1999) Effects of justice conditions on discrete emotions. Journal of Applied Psychology 84(5): 786-794. 
Westen D (1994) Toward an integrative model of affect regulation: Applications to social-psychological research. Journal of Personality 62(4): 641-667.

Wubben MJ, De Cremer D and Van Dijk E (2009) How emotion communication guides reciprocity: Establishing cooperation through disappointment and anger. Journal of Experimental Social Psychology 45(4): 987-990.

Zeelenberg M, Van Dijk W, Manstead A and Van der Pligt J (2000) On bad decisions and disconfirmed expectancies: The psychology of regret and disappointment. Cognition and Emotion 14(4): 521-541.

Genevieve Johnson is a doctoral candidate in Industrial and Organizational Psychology at the University of Oklahoma, USA. Her current research interests include emotions in the workplace, ethical decision making, leadership, interpersonal and organizational communication, and performance feedback. She has been published in journals including The Leadership Quarterly and Journal of Computer-Mediated Communication. [Email: johnson.gen@ou.edu]

Shane Connelly is an associate professor in the Department of Psychology at the University of Oklahoma, USA. Dr Connelly's focal research interests include leadership, emotions in the workplace and ethical decision making. She has published over 80 scholarly articles and chapters in a variety of journals including The Leadership Quarterly, Human Performance, Cognition and Emotion, Ethics and Behavior and International Journal of Conflict Management. Her research addresses issues such as how emotions and emotion regulation influence the attitudes and performance of leaders and their followers, what skills contribute to leader performance over time, the influence of emotions on moral disengagement and ethical decision making in organizations, and how to assess and train research ethics. Dr Connelly is also a founding member and serves on the executive committee of the Center for Applied Social Research. [Email: sconnelly@ou.edu] 